\title{
PENSANDO O ENSINO DA GEOMETRIA NO CICLO DE ALFABETIZAÇÃO
}

\author{
Sandra Mara Moreno Ribeiro ${ }^{1}$
}

\begin{abstract}
Resumo: Este trabalho apresenta o relato de experiência realizado com um grupo de vinte e quatro professoras alfabetizadoras da Rede Municipal de Uberlândia durante encontros de formação do Pacto Nacional pela Alfabetização na Idade Certa (PNAIC) na área de Linguagem/Matemática, ocorridos no ano de 2014 e teve como eixo norteador o Caderno 5, cujo tema é a Geometria. O relato teve como objetivo possibilitar às professoras a reflexão sobre a prática pedagógica; perceberem o que sabem e o que não sabem sobre o eixo estruturante: Geometria; conhecerem os direitos de aprendizagem que precisam ser garantidos às crianças por meio do ensino da geometria e a vivenciarem e partilharem práticas mais dinâmicas, lúdicas e significativas que permitam a criança perceber a presença e função da geometria no seu cotidiano. Verificou-se que referir-se à Geometria corresponde aos conceitos de medida dos espaços, todavia amplia e permite inter-relações com outros eixos estruturantes e outras áreas do conhecimento.
\end{abstract}

Palavras-chave: Formação de professores. Alfabetização Matemática. Geometria.

\section{THINKING ABOUT TEACHING GEOMETRY DURING THE LITERACY CICLE}

\begin{abstract}
This paper presents the experience account conducted during training meetings of the National Pact for Literacy at the Right Age (Pacto Nacional pela Alfabetização na Idade Certa - PNAIC) in the area of Language / Mathematics. Those training meetings occurred in 2014 with a group of twenty-four literacy teachers of Uberlândia's municipal educational system. This experience account had as its guiding principle the book Caderno 5 , whose theme is Geometry. The account aimed to enable the teachers to reflect on the pedagogical practice; to realize what they know and what they do not know about the structural axis: Geometry; to have contact with the knowledge about learning rights that need to be secured to children through geometry teaching; to experience and to share the most dynamic, playful and meaningful practices that allow the child to notice geometry's presence and function in their daily lives. It was noticed that, for the teachers who participated in the research, geometry corresponds to the concept of space measuring, but it expands and allows interrelations with other structural axis and other areas of knowledge.
\end{abstract}

Keywords: Teacher training. Literacy, Mathematics. Geometry.

\section{Introdução}

A Geometria é um dos eixos da matemática e seu conteúdo está presente desde as séries iniciais. Nota-se que o ensino da Geometria no ciclo de alfabetização não é prioridade, sendo na maioria das vezes deixado para o final do ano, caso haja tempo para trabalhá-lo. Percebe-se também que, quando trabalhado, este ocorre de forma totalmente desvinculada

\footnotetext{
${ }^{1}$ Licenciada em Pedagogia pelo Centro Universitário de Campo Grande/MS. Pós-Graduada em Alfabetização pelas Faculdades Integradas de Jacarepaguá/RJ.
} 
do cotidiano das crianças, não permitindo que percebam a importância e nem atribuam significado a tal conteúdo. O ensino da Geometria tem se limitado ao ensino das figuras geométricas planas e, às vezes, as espaciais, e quase exclusivamente a identificação, reprodução das figuras e memorização dos nomes.

O estudo do Caderno 5 do PNAIC amplia nosso olhar sobre o tema e destaca quais direitos de aprendizagem precisam ser garantidos aos alunos e, principalmente, de que maneiras isso é possível considerando a importância da ludicidade nessa fase da infância.

\section{Desenvolvimento}

Para a realização do trabalho com o ensino da Geometria foi elaborada uma sequência didática prevista para doze horas contendo, entre outras atividades, vídeos relacionados ao tema, leituras deleites, jogos, estudo em grupo, manipulação de materiais (embalagens, objetos, sólidos geométricos), construção de maquete e de planta baixa, brincadeira da caça ao tesouro. É oportuno mencionar alguns desses momentos que merecem ser destacados.

Para iniciar o trabalho com os conteúdos do eixo de Geometria e verificar os conhecimentos prévios das professoras em relação ao tema que seria trabalhado, foi realizado um jogo proposto no caderno intitulado Jogos na Alfabetização Matemática, que faz parte dos cadernos distribuídos no curso de formação do Pacto Nacional pela Alfabetização na Idade Certa (PNAIC). O nome do jogo é: "Jogo das Figuras”. Após explicar as regras do jogo, a orientadora Sandra sorteou uma carta contendo uma figura composta por figuras geométricas planas. Na medida em que ela ia descrevendo a posição das figuras geométricas planas, as professoras iam desenhando tentando formar a figura da carta sorteada. Nesta primeira atividade já foi possível perceber as limitações em relação aos conteúdos de Geometria, houve muita dificuldade. 
Muitas professoras não lembravam o que era um trapézio, não sabiam como desenhar um quadrado rotacionado, desconheciam os diferentes tipos de triângulos e os diferentes tipos de ângulos, apresentaram dificuldades com a lateralidade. Elas acharam o jogo bastante interessante, porém consideraram algumas figuras difíceis para serem utilizadas com as crianças no ciclo de alfabetização.

Foi discutido o conceito que temos construído sobre quadrado, retângulo, triângulo, falando sobre os atributos relevantes e irrelevantes. Muitas professoras afirmaram que nunca tinham parado para pensar sobre isso, no quanto os atributos irrelevantes podem induzir a criança ao erro, podem levar a construção errônea de um conceito. Uma das professoras chamou a atenção para o cartaz com as figuras geométricas afixado em sala de aula, normalmente contendo um único modelo de cada figura (no mesmo tamanho, na mesma posição, na mesma cor) e permanecendo o mesmo cartaz o ano todo na sala. Discutiu-se a importância de apresentar as crianças figuras geométricas em diferentes posições, cores e tamanhos.

Solicitou-se que as professoras levassem para a próxima formação embalagens e objetos contendo formas geométricas. Diante das embalagens e objetos que foram levados as professoras compararam com os sólidos geométricos, para ver com qual deles a embalagem ou objeto se parecia. Elas contornaram as faces das embalagens e objetos para ver qual figura plana aparecia, realizaram a planificação e depois a reconstrução, juntando novamente as faces e identificando o número de faces, de vértices e arestas de cada figura formada. As embalagens foram ainda utilizadas na construção de maquetes e plantas baixas, sendo que um grupo fez a maquete e planta de uma sala de aula, outro grupo a de uma escola e um terceiro grupo de uma cidade.

Com estas atividades as professoras perceberam que é possível trabalhar as figuras geométricas planas e espaciais de maneira dinâmica e significativa. Discutiram-se algumas 
possibilidades de trabalhar as noções de localização e movimentação no espaço físico a partir das maquetes e plantas baixas com as crianças.

Foram dadas sugestões de atividades que possibilitassem aos alunos a construção de noções de localização e movimentação no espaço físico, visto que este também é um dos objetivos da Geometria no ciclo de alfabetização, e não apenas o trabalho com as figuras geométricas, sendo realizadas duas atividades nas quais as professoras alfabetizadoras participaram com bastante entusiasmo.

A primeira atividade consistiu na realização do jogo: "Na direção certa", também proposta no caderno de jogos já mencionado anteriormente. Ao invés das professoras realizarem o jogo em sala, no tabuleiro sugerido, o jogo foi adaptado para ser realizado no pátio. O tabuleiro foi traçado no chão com piso quadriculado, foi construído um dado bem grande e as professoras foram os peões (marcadores). Cada professora, na sua vez, lançava o dado e retirava uma seta. Em seguida deveria andar o número de casas indicadas no dado na direção indicada pela seta (direita, esquerda, frente, direita e em frente, etc.). Uma outra professora ia marcando o caminho percorrido usando durex colorido. O jogo foi bastante animado e disputado. A sugestão de primeiro trabalhar as noções topológicas e de lateralidade usando como referência o corpo da criança, para depois realizar o jogo no tabuleiro foi considerada bastante válida, pois é por meio dos sentidos e movimentos que a criança constrói suas noções espaciais.

Outra atividade proposta foi a brincadeira da Caça ao Tesouro. Como havia duas turmas de formação no mesmo dia e horário, as professoras de ambas as turmas, foram orientadas a esconderem um tesouro e elaborarem pistas para as professoras cursistas da outra turma encontrar. A regra era usar as palavras: em cima, embaixo, direita, esquerda, frente, atrás, dentro, fora. As pistas foram entregues e as professoras saíram à caça de seus tesouros. Após encontrarem foi solicitado que desenhassem o mapa do caminho percorrido 
da sala até o tesouro. A empolgação foi geral, muitas professoras afirmaram que iriam realizar a atividade com os alunos e perceberam como é possível trabalhar o conteúdo de Geometria de forma lúdica e interativa, explorando juntamente a escrita e a leitura.

Ao trabalhar as conexões da Geometria com a Arte, as professoras foram divididas em três grupos e cada grupo deveria ler sobre um tema (no próprio Caderno 5 e textos complementares que foram entregues), elaborar um trabalho artístico e destacar as possibilidades de trabalho com as figuras geométricas. Os temas foram mosaico, origami e tangram. O que mais chamou a atenção é que entre as professoras que ficaram no grupo do tangram, nenhuma delas havia trabalhado com o quebra cabeça chinês. Afirmaram que não achavam significativo, mas que passaram a ter um novo olhar, a reconhecer o potencial do material no trabalho com as crianças e a vislumbrar possibilidades.

O grupo que ficou com o mosaico, falou do artista apresentado no Caderno 5, Escher, mas também destacando a importância de reconhecer os artistas locais, falaram de Geraldo Queiroz e observaram a satisfação de produzir um mosaico, de brincar com as cores e com as formas, compondo e decompondo figuras.

O outro grupo explicou o que é origami e contou a história: "O barquinho de papel”. Na medida em que ouviam a história as professoras tinham que realizar dobraduras em uma folha sulfite que haviam recebido. Ao finalizar a história foi solicitado que abrissem o papel e fizessem um traço sobre as marcas formadas, observando as figuras geométricas que apareciam. Poucas professoras disseram ter realizado trabalho com dobraduras com seus alunos, mas foram unânimes em reconhecer o quanto as crianças gostam deste tipo de trabalho. Assim, foram apresentadas e discutidas algumas sugestões de trabalho com origamis. Como tarefa de casa foi solicitado que as professoras pesquisassem e fizessem a releitura de uma obra de um artista que utilizasse traços geométricos. 
Diante do interesse demonstrado pelo grupo no curso de formação, da pouca familiaridade e uso da técnica, da motivação que é apresentada pelas crianças e das possibilidades de trabalho com conceitos matemáticos foi que se pensou em uma oficina de origami para o seminário de encerramento do Pacto Nacional pela Alfabetização na Idade Certa.

\section{Considerações finais}

Normalmente os professores que ensinam Matemática nos anos iniciais não possuem formação específica em Matemática, o que gera insegurança frente a conteúdos dessa disciplina. Os professores devem refletir e tomar consciência da sua formação anterior e da necessidade de um novo olhar para a Matemática a ser ensinada na educação básica. Desta forma, a formação continuada dos professores é essencial, pois disponibiliza novos saberes e alternativas para que o docente possa renovar, aperfeiçoar e refletir suas práticas, suprindo as lacunas deixadas na formação inicial.

Refletindo sobre o ensino e aprendizagem de Geometria na formação continuada é possível trabalhar com os professores de forma a contribuir para um planejamento adequado, esclarecendo dúvidas e propondo atividades que estimulem o ensino deste conteúdo de maneira mais lúdica e significativa.

\section{Referências}

BRASIL. Ministério da Educação, Secretaria de Educação Básica, Pacto Nacional pela Alfabetização na Idade Certa: Geometria. Brasília, 2014.

Ministério da Educação, Secretaria de Educação Básica, Pacto Nacional pela Alfabetização na Idade Certa: Jogos na Alfabetização Matemática. Brasília, 2014. 